\title{
CRÍTICAS AO HISTORICISMO E RACIONALIDADE APODÍTICA NAS TESES SOBRE O CONCEITO DE HISTÓRIA DE WALTER BENJAMIN
}

\section{CRITICISM TO HISTORICISM AND APODITICAL RATIONALITY IN THESES ABOUT THE CONCEPT OF HISTORY OF WALTER BENJAMIN}

\author{
Deibson Joaquim dos Santos ${ }^{1}$ \\ Edmilson Alves de Azevêdo ${ }^{2}$
}

Recebido: 06/2018

Aprovado: 06/2018

\begin{abstract}
Resumo: A modelo apodítico de investigação científica, desde o século XVI, tornou-se predominante nas pesquisas científicas, independente dos objetos de estudos e das especificidades dos campos de pensamento. Dessa forma, o conhecimento histórico foi influenciado pela racionalidade lógico e matemática, inclusive culturas historiográficas foram constituídas a parti desse modelo: o Historicismo, por exemplo, possuí essas características. W. Benjamin, nas teses Sobre o Conceito de História, formulou várias críticas a cultura historiográfica do Historicismo, acusou os pensadores desse campo argumentativo de desenvolverem empatia com a classe dominante. Por isso, neste texto, procuramos refletir sobre as motivações de Walter Benjamin e sobre a forma como o Historicismo usou a razão apodítica em seus objetivos políticos, de modo que estimulou a manutenção da ordem burguesa.
\end{abstract}

Palavras-chave: Razão apoditíca, Walter Benjamin, historicismo.

\begin{abstract}
The apodic model of scientific research, since the sixteenth century, has become predominant in scientific research, independent of the objects of study and the specificities of the fields of thought. In this way, historical knowledge was influenced by logical and mathematical rationality, including historiographical cultures were constituted from this model: Historicism, for example, has these characteristics. W. Benjamin, in the Theses on the Concept of History, made several criticisms of the historiographical culture of Historicism, accused the thinkers of this argumentative field of developing empathy with the ruling class. Therefore, in this text, we try to reflect on the motivations of Walter Benjamin and on the way in which Historicism used the apodic reason in its political objectives, in such a way that it stimulated the maintenance of the bourgeois order.
\end{abstract}

Keywords: Apodic reason, Walter Benjamin, historicism.

\section{Introdução}

\footnotetext{
${ }^{1}$ Mestrando do Programa de Pós Graduação em Filosofia da Universidade Federal da Paraíba - UFPB.

2 Professor Titular na UFPB. Membro do Programa Integrado de Pós-Graduação em Filosofia - PIPF/UFPBUFPE-UFRN. Coordenador do Grupo Hermes de Pesquisa.
} 
Os métodos para a consecução do pensamento Histórico motivaram muitos debates ao longo dos séculos: ora preocuparam filósofos, ora historiadores e outros teóricos, uma vez que as culturas historiográficas contribuem para a formalização de culturas históricas e são instrumentos para a construção da consciência histórica de uma sociedade.

As culturas historiográficas são construídas pela reunião de pensadores que compartilham teorias, métodos, (NASCIMENTO, 2009). Mas, são produzidas a parti de lugares comuns compartilhados pela filosofia e demais ciências humanas, uma vez que os discursos dos teóricos extrapolam as fronteiras de suas ciências e são utilizados por outros pesquisadores que comungam das mesmas concepções teóricas, metodológicas e percepção sociocultural em vários campos de saberes científicos.

Uma cultura historiográfica pode ser delimitada por meio de várias perspectivas, incluindo seus métodos, associações teóricas com outras disciplinas ou modelo de racionalidade, especialmente quando tratamos da epistemologia do conhecimento histórico.

Nessa perspectiva, Walter Benjamin teceu várias críticas, nas Teses Sobre conceito de História, aos modelos de cultura historiográficas mais disseminadas naquela época. Todavia, dentre as críticas de Benjamin, interessa-nos àquelas direcionadas aos usos da razão apodítica na historiografia na época, pois é à base metodológica para os modelos de escrita do conhecimento histórico que predominavam nas instituições acadêmicas naquele período.

Entretanto, para a continuidade de nosso diálogo algumas indagações são pertinentes: Quais as associações historiográficas foram criticadas por W. Benjamin? Como a razão apodítica se apresentava na escrita histórica naquele período? De que forma Walter Benjamin criticou esses modelo de racionalidades no âmbito do conhecimento histórico?

Dentre os campos argumentativos da historiografia criticados por W. Benjamin nas teses, o Historicismo se destacou. No entanto, cabe enfatizarmos que os pensadores historicistas seguiam orientações positivistas ou kantianas, mas o uso da racionalidade apodítica era a característica essencial desses teóricos, pois objetivavam a História ciência. Além disso, W. Benjamin criticou algumas correntes do "materialismo histórico", sobretudo, aquelas que acreditavam na vitória da classe oprimida através da "falência" do sistema capitalista. Mas não focaremos nas críticas ao "materialismo histórico", porque não é o nosso objetivo nas reflexões existentes nesse texto, didaticamente, focaremos apenas no uso da racionalidade opodítica pelos historicistas. 


\section{O historicismo apodítico}

Após o século XVI houve a reorganização epistemológica do conhecimento humano em torno da racionalidade cientifica, pois a lógica analítica, que desde a época Grega Clássica reivindicava a posição de "ciência teórica dedutiva" (TOULMIN, 2006, pag.253), ganhou espaço significativo em detrimento aos outros modelos para a verificação dos argumentos.

Além disso, "o more geométrico" - a proposta cartesiana efetivada por Espinoza no século XVII - "procedendo de evidência em evidência, não deixando lugar a nenhuma opinião controvertida. Ambicionava elaborar uma ciência onde todas as teses seriam evidentes" (ROHDEN, 1998, pag. 251). Nesse modelo de racionalidade predominante até o século XIX, “as premissas são verdadeiras, exatas, e as conclusões têm o mesmo caráter" (ROHDEN, 1998, pag. 254).

Assim, a racionalidade apodítica tornou-se hegemônica na produção do conhecimento cientifico, colocando os demais modelos de racionalidades às margens das ciências e da produção do conhecimento.

Dessa forma, os campos do conhecimento humano que usavam a dialética ou retórica para a verificação da verossimilhança dos argumentos, perderam seus status de ciência, uma vez que "a racionalidade demonstrativa foi tida, por muito tempo, não apenas como ideal de razão, mas a própria expressão fidedigna de toda forma de racionalidade” (NARBAL, 2011, pag. 276).

Por isso, as ciências adequaram-se a racionalidade apodítica independente de suas especificidades ou das características de seus objetos de estudo, uma vez que a busca pela verdade atemporal e inquestionável tornou-se primordial na realização e seus objetivos, já que o "conhecimento das causas e necessidades caracteriza a ciência apodítica, constituindo a demonstração (apódeixis), formando o silogismo científico. Este supõe uma necessidade formal, própria desta forma de raciocinar" (ROHDEN, 1998, pag. 256).

No âmbito do pensamento historiográfico, a reorientação epistemológica buscava a formalização de um modelo de conhecimento histórico demonstrativo, por meio de uma racionalidade que buscava o verdadeiro o fato histórico. Nesse sentido, os historicistas reunidos em positivistas ou kantianos, de nacionalidade alemã ou francesa - empreenderam a reformulação dos métodos históricos, ou melhor, a formalização modelo de cultura historiográfica apodítica. 
Há de se dizer que os historicistas foram influenciados por pensadores que lhes antecederam, já que esse "Tal ideal epistêmico e cognitivo perpassou as ideias de vários pensadores de Descartes a Carnap, passando por Spinoza, Kant, Leibniz e por todos os positivistas lógicos" (NARBAL, 2011, pag. 273), possibilitando uma hierarquização em que as ciências da natureza são super valorizadas em detrimentos as ciências humanas.

Esse esquecimento por parte dos lógicos e filósofos em geral apontado por Perelman e também, no Brasil, por Rohden, sinaliza um tipo de hierarquia entre ciências da natureza e ciências humanas, pressuposta ou admitida, que é ainda tributária de uma concepção de razão apodítica ou demonstrativa e que se inspira e toma como modelo de reflexão e de produção do conhecimento aquele que se dá segundo um "more geometrico", inerente à Matemática e à Física (NARBAL, 2011, pag. 273).

$\mathrm{Na}$ Tentativa de conceber um modelo de conhecimento histórico "atemporal" "necessário", "imutável” e "verdadeiro" os historicistas abandonaram as fontes históricas que não tivessem origem em documentos oficiais ou não fizessem parte dos acervos oficiais, assim descartavam aquelas que não pertenciam aos grupos sociais dominantes, uma vez que as classes oprimidas não detêm o controle das instituições mantenedoras dos arquivos históricos da memória coletiva.

Além disso, esses pensadores propuseram um modelo historiográfico inspirado no silogismo lógico matemático, já que para testar a validade dos dados apresentados, seguia-se o princípio que buscava descartar argumentos "falsos" através do raciocínio dedutivo: para esses pensadores, apenas era possível obter dados verdadeiros em documentos oficiais.

Nessa perspectiva, "uma vez demonstrada uma proposição, em lógica, a argumentação 'forte' (dedutiva) se torna necessária e as demais provas são consideradas supérfluas" (ROHDEN, 1998, pag. 264) e não são passiveis de questionamentos. Assim, os argumentos históricos obedecem a uma relação de "causa e efeito".

No entanto, aos seguirmos esse modelo, podemos supor, hipoteticamente, que os eventos históricos são indissociáveis, estão todos conectados por relações causais, ou seja, que um fato histórico foi causado, necessariamente, pelos efeitos de outro acontecimento histórico anterior. Para alegorizar o nosso raciocínio, tomemos como exemplo a Revolução Francesa e a Revolução no Haiti.

Supondo que a Revolução Francesa seja o primeiro evento investigado por pensadores historicistas e a Revolução do Haiti o segundo fato histórico pesquisado, ao nos apropriarmos do método desses pensadores, supomos que as "relações causais" entre os eventos históricos 
possibilitam a proposição de uma historiografia linear e lógica para os acontecimentos históricos, assim surgem às condições para deduzir que existem implicações "necessárias" que coloca um evento como efeito do acontecimento anterior.

Não é nosso objetivo questionar as particularidades entre os ideais de liberdade dos franceses e àqueles pertencentes à Revolução no Haiti ou sugerir que os acontecimentos na Revolução Francesa não motivaram alguns aspectos da Revolução Haitiana, uma vez que as ideias francesas possivelmente circularam entre metrópole e colônia.

Mas, nesse caso, a redução dos fatos a proposições analíticas desconstroem o caráter lingüístico dos argumentos usados pelos revolucionários franceses e haitianos em suas revoluções, assim como impede a rememoração das lutas da classe oprimida, uma vez que "o fato como premissa é um fato não-controverso" (PERELMAN, 2005, pag. 76) e possui status de "verdade inquestionável", como pretendiam os historicistas, desprovendo os fatos de todos os questionamentos possíveis, já que esse grupo de pensadores reivindicava-se imparcial.

No texto "origem do Drama Barraco Alemão" W. Benjamin argumenta que "a ideia é da ordem da linguagem, mais precisamente a essência da palavra, aquele momento que esta é símbolo, [...] cabe ao filosofo restituir pela representação o primado do caráter simbólico da palavra, no qual a ideia chega ao seu autoconhecimento" (BENJAMIN, 2011, pag.25). Nesse sentido, podemos supor, na condição de exemplo, que o termo "liberdade", durante a Revolução Francesa, provavelmente não tivesse a mesmo sentido político quando foi usado pelos haitianos. Talvez, os franceses referiam-se as questões políticas entre a nobreza, o clero absolutista e a burguesia, enquanto os escravos no Haiti usavam o termo para reivindicar o fim do sistema escravagista ou a independência entre a metrópole e a colônia, isto é, a hermenêutica dos conceitos usados pelos revolucionários é primordial para compreender o sentido das lutas que eles travaram.

Seguindo esse raciocínio, percebemos que os livros, sobretudo os livros didáticos, descrevem que os eventos no Haiti estimularam a revolta do malês na Bahia, ou seja, somamse acontecimentos uns aos outros, criando uma linha sequencial organizada logicamente para preencher linearidade da história. Mas os eventos têm sua origem vinculada aos eventos da burguesia.

Nesse modelo historiográfico, despreza-se a importância do Islã na vida dos Maleses que, provavelmente, tenha sido inspiração mais significativa para instrumentar a revolta. Mas esses dados são desconsiderados na propositura dos argumentos históricos historicistas, devido às "relações causais dedutivas" entre os eventos históricos. 
A categoria suprema da história do mundo, que garante a univocidade dos acontecimentos, é a culpa. Cada momento dessa história está marcado pela culpa e implica a culpa. Causa e efeito nunca poderão ser categorias decisivas na estrutura da história do mundo, porque não podem determinar nenhuma totalidade. A lógica terá de demonstrar o postulado segundo o qual nenhuma totalidade enquanto tal pode ser causa ou efeito. A concepção racionalista da História comete o erro de considerar causa ou efeito qualquer totalidade histórica (ou seja, um determinado estado do mundo). Um estado do mundo, no entanto, é apenas, e sempre, culpa (na sua relação com um outro, que virá depois dele (BENJAMIN, 2012, pag. 26).

Na perspectiva benjaminiana a linguagem é um espaço no qual as lutas são travadas, uma vez que com linguagem, estimulamos emoções, rememoramos o passado, nos apropriamos do mundo e atuamos historicamente nele, isto é, "Ganhar ou perder uma guerra é qualquer coisa que, a acreditar no espírito da linguagem, penetra tão fundo na trama da nossa existência que nos torna para sempre mais ricos ou mais pobres em quadros, imagens, descobertas" (BENJAMIN, 2012, pag. 67).

A nossa pretensão ao usar os acontecimentos históricos descritos nos parágrafos anteriores era refletir como os métodos de consecução do conhecimento histórico adotado pelos historicistas, desconectaram os fatos do seu contexto cultural e de sua ligação com o presente, criando uma cultura histórica homogênea e universal.

Esse método foi criticado nas teses Sobre o Conceito de História quando nosso pensador citou o historiador Fustel de Coulanges. Segundo W. Benjamin, Fustel de Coulanges sugeriu "ao historiador que pretenda reconstruir uma época que ignore tudo o que conhece do desenrolar histórico posterior" (BENJAMIN, 2012, pag. 09).

Ao comentar a tese VII Michel Löwy argumentou que, "a polêmica contra Fustel de Coulanges - historiador francês positivista e reacionário do século XIX - continua a das teses anteriores contra Ranke e o historicismo alemão: o passado pode ser compreendido somente a luz do presente, sua imagem verdadeira e celebre e furtiva - 'lampeja'”.

Assim, os pensadores historicistas pretendiam realizar uma História verdadeira, imparcial e detentora dos acontecimentos históricos na forma como aconteceram. Para isso condenavam quaisquer tipos de reflexão sobre os desdobramentos dos fatos históricos no presente e a investigação dos acontecimentos a parti de lugares comuns argumentativos compartilhados pela filosofia e demais ciências humanas. 
Para W. Benjamin a postura dos pensadores positivistas não permitia que reconhecessem o passado da forma como ele aconteceu, porque "Articular historicamente o passado não significa reconhecê-lo 'tal como ele foi' Significa apoderarmo-nos de uma recordação (Erinnerung) quando ela surge como um clarão num momento de perigo".

Por outro lado, inexistência de base teórica na proposta historicistas, motivada pela suposta busca por imparcialidade, também foi alvo das críticas de nosso teórico, uma vez que os acontecimentos históricos são somados e "acumulados para preencher o tempo vazio e homogêneo", de modo que os objetivos consistem em narrar os acontecimentos históricos na condição de "fatos verdade" sem a interferência dos argumentos produzidos a parti dos campos de pensamento na qual o pesquisador é filiado. Ou seja, o "método é aditivo: oferece a massa dos fatos acumulados para preencher o tempo vazio e homogêneo" (2012, pag. 19).

Segundo Michel Löwy (2005, p. 131) é:

exatamente o mesmo tempo dos bancos de investimento e dos grandes estabelecimentos de credito; e o tempo da marcha dos lucros produzidos por um capital...; tempo verdadeiramente homogêneo, pois traduz, pois transmite em cálculos homogêneos... pois transpõe em uma linguagem (matemática) homogênea as inúmeras variedades de ansiedades e de fortunas.

Trata-se da "concepção historicista quantitativa do tempo histórico como acumulação" (LÖWY, 2005, pag. 131), isto é, o tempo teleológico pautado no capital. W. Benjamin não criticou apenas a organização do tempo Histórico proposto pelos historicistas, mas também o modo como a cultura histórica criada por eles acabou estimulando a manutenção do poder pela classe social dominante em detrimento a classe oprimida.

Cabe enfatizarmos que W. Benjamin considerou os fundamentos das críticas historicistas aos modelos de culturas historiográficas que lhes antecederam, mas não descartou o "perigo" da historiografia historicista para a cultura, sobretudo a cultura inerente as classes oprimidas, uma vez que os usos da racionalidade apodítica a serviço da empatia com a classe dominante é o mecanismo que fundamenta a ideologia burguesa, isto é, a ciência histórica como instrumento de consciência histórica para os objetivos da classe dominante. Nesse sentido, afirmou ele "Essa crítica do historicismo tem o seu peso. A sua referência às ciências da natureza, porém - como "a ciência por excelência" -, põe à vista toda a dimensão da perigosa problemática da questão cultura" (BENJAMIN, 2012, pag. 76).

Não obstante, para José Carlos Reis esses pensadores foram responsáveis pela disseminação do conhecimento históricos e profissionalização dos pensadores, uma vez que "a 
história se profissionalizou definitivamente: numerosas cadeiras na universidade, sociedades cientificas, coleções de documentos, revistas. Manuais, publicação de textos históricos, um público culto comprador de livros” (REIS, 1996, pag. 17).

No entanto, os historicistas contribuíram para a difusão da cultura historiográfica burguesa provocando o silenciamento das classes sociais oprimidas. Para W. Benjamin esse comportamento é resultado da empatia com a classe social dominante (BENJAMIN, 2012, provavelmente, esse sentimento rendeu-lhe o sucesso que obtiveram e a abertura nas instituições controlada pela burguesia.

Michel Löwy (2005) e Jose Carlos Reis (1996) defendem que o historicismo surgiu a parti de lugares comuns ao discurso da burguesia e fundamentado nos no pensamento de historiadores reacionários.

Por isso é uma cultura historiográfica doutrinadora da moralidade e tradição burguesa, em detrimento a cultura das classes oprimidas, como alertou W. Benjamin. Por esse motivo não "condenamos" o uso da razão apodítica pela historiografia, mas refletimos sobre as formas como o historicismo utilizou esse modelo de racionalidade para promover a manutenção da ordem burguesa.

\section{Argumentos finais}

É no presente que escolhemos o nosso passado: se imaginarmos que essa concepção de História é uma definição resumidissíma do conceito de História que W. Benjamim propôs na amplitude de suas reflexões, entenderemos o papel ativo do pesquisador na tessitura do conhecimento histórico, uma vez que suas escolhas contribuem para o fortalecimento da lutas de classe ou silenciamento da classe oprimida.

Nesse sentido, compreendemos que o modelo de racionalidade apodítico não é causa da aproximação dos historicistas com as classes dominantes, mas a empatia que estes pensadores desenvolveram com as classes opressoras. Sobre isso Michel Löwy argumentou que: "continuando sua polemica contra o historicismo, Benjamin formula uma curiosa alegoria. Pode-se interpretá-la assim: a prostituta "era uma vez", instalada no bordel 'historicismo', recebia os vencedores um após outro".

Provavelmente, o uso da razão da apodítica a serviço dos objetivos do historicismo, é uma das causas da existência dessa Cultura Histórica enaltecedora da classe dominante, em detrimento a classe oprimida, que ainda vivenciamos em nossos dias. 


\section{Referências}

BENJAMIN, Walter. Origem do drama barroco alemão. Trad. João Barrento. Belo Horizonte: Autêntica, 2011.

O anjo da História. Trad. João Barrento. Belo Horizonte: Autêntica, 2012.

LÖWI, Michel. Benjamin: aviso de incêndio: uma leitura das teses "Sobre o conceito de História. Trad. Wanda Nogueira Caldeira Branr; Jeanne Marie Gagnebin (trad. das Teses). São Paulo: Boitempo, 2005.

NASCIMENTO, George Silva do. Cultura historiográfica e Cultura histórica: conceitos antagônicos ou complementares? (Anais) In. 30. Seminário Nacional de História da Historiografia: aprender com a história? Ouro Preto: Edufop, 2009.

MARSILLAC, Narbal de. Racionalidade retórica e argumentativa. Princípios. Natal: v.18, n.30, jul - dez. 2011.

PERELMAN, Chaïm; OLBHECHTS-TYTECA, Lucie. Tratado da Argumentação: nova retórica. São Paulo: Martins Fontes, 2005.

REIS, José Carlos. História: entre a filosofia e a ciência. São Paulo: Editora Ática, 1996.

ROHDEN, Luiz. Racionalidade retórica, uma linguagem filosófico-hermenêutica em Aristóteles. Síntese Nova Fase, Belo Horizonte: v. 25, n. 81, 1998.

TOULMIN, Stephen E. Os usos do argumento. São Paulo: Martins Fontes, 2006. 